University of Nebraska - Lincoln DigitalCommons@University of Nebraska - Lincoln

USGS Staff -- Published Research

US Geological Survey

2017

\title{
Design Tradeoffs in Long-Term Research for Stream Salamanders
}

Adrianne B. Brand

USGS Patuxent Wildlife Research Center

Evan H. Campbell Grant

USGS Patuxent Wildlife Research Center, ehgrant@usgs.gov

Follow this and additional works at: https:// digitalcommons.unl.edu/usgsstaffpub

Part of the Geology Commons, Oceanography and Atmospheric Sciences and Meteorology Commons, Other Earth Sciences Commons, and the Other Environmental Sciences Commons

Brand, Adrianne B. and Campbell Grant, Evan H., "Design Tradeoffs in Long-Term Research for Stream Salamanders" (2017). USGS Staff-- Published Research. 1037.

https://digitalcommons.unl.edu/usgsstaffpub/1037

This Article is brought to you for free and open access by the US Geological Survey at DigitalCommons@University of Nebraska - Lincoln. It has been accepted for inclusion in USGS Staff -- Published Research by an authorized administrator of DigitalCommons@University of Nebraska - Lincoln. 


\title{
Design Tradeoffs in Long-Term Research for Stream Salamanders
}

\author{
ADRIANNE B. BRAND, USGS Patuxent Wildlife Research Center, SO Conte Anadromous Fish Research Center, 1 Migratory Way, Turners Falls, \\ MA 01376, USA \\ EVAN H. CAMPBELL GRANT, ${ }^{1}$ USGS Patuxent Wildlife Research Center, SO Conte Anadromous Fish Research Center, 1 Migratory Way, \\ Turners Falls, MA 01376, USA
}

\begin{abstract}
Long-term research programs can benefit from early and periodic evaluation of their ability to meet stated objectives. In particular, consideration of the spatial allocation of effort is key. We sampled 4 species of stream salamanders intensively for 2 years (2010-2011) in the Chesapeake and Ohio Canal National Historical Park, Maryland, USA to evaluate alternative distributions of sampling locations within stream networks, and then evaluated via simulation the ability of multiple survey designs to detect declines in occupancy and to estimate dynamic parameters (colonization, extinction) over 5 years for 2 species. We expected that finescale microhabitat variables (e.g., cobble, detritus) would be the strongest determinants of occupancy for each of the 4 species; however, we found greater support for all species for models including variables describing position within the stream network, stream size, or stream microhabitat. A monitoring design focused on headwater sections had greater power to detect changes in occupancy and the dynamic parameters in each of 3 scenarios for the dusky salamander (Desmognathus fuscus) and red salamander (Pseudotriton ruber). Results for transect length were more variable, but across all species and scenarios, $25-\mathrm{m}$ transects are most suitable as a balance between maximizing detection probability and describing colonization and extinction. These results inform sampling design and provide a general framework for setting appropriate goals, effort, and duration in the initial planning stages of research programs on stream salamanders in the eastern United States. Published 2017. This article is a U.S. Government work and is in the public domain in the USA.
\end{abstract}

KEY WORDS Desmognathus fuscus, Eurycea bislineata, microhabitat, monitoring design, multistate model, occupancy, Pseudotriton ruber, stream network, stream salamander.

Long-term research and monitoring programs may fail to provide timely, useful information for natural resource management because of poor initial design, inefficiency of execution, or infrequent review and evaluation (Lindenmayer and Likens 2010). Key components for success include 1) careful a priori consideration of the biological system and factors that may contribute to change in a monitored system, 2) probabilistic selection of sample units and a sampling design that accommodates heterogeneity in detection probability, and 3) early analysis of data to allow adjustment of monitoring protocols or goals. In particular, failure to evaluate the spatial allocation of effort and sampling protocols designed to maximize detection can limit the efficacy of any monitoring program. Further, obtaining information on the possible causes of population or distributional changes, rather than simply describing a trend in a population, is important for informing resource management decisions.

Occupancy may be a suitable state variable for many monitoring programs, especially those that seek to understand

Received: 31 August 2016; Accepted: 6 June 2017

${ }^{1}$ E-mail: ehgrant@usgs.gov the distribution or dynamics of populations across large areas where estimation of population abundance may be infeasible, or when interest is on the number of populations present across a set of defined habitat patches. Occupancy models that account for imperfect detection (i.e., the failure to observe a species when it is present during a survey) provide unbiased estimates of occupancy probability for a single time period, and rate parameters, local colonization, and extinction, when detection and nondetection data are available for multiple seasons or years (MacKenzie 2006). Time series of occupancy estimates (i.e., trends) are a natural outcome of this monitoring design, and incorporating covariates into the analysis allows estimation of factors contributing to variation in local extinction or colonization probabilities, and modifying these rates can then be management targets. Critical to this process is matching the scale of the parameter of interest to that of potential management actions, and defining sampling schemes that may most efficiently inform management (e.g., size, length, or area of study sites).

Salamander populations in headwater streams are generally considered stable (Hairston 1987, Green 2003), in part because of the spatial complexity of dendritic stream networks, where the inherent connectivity characteristic of these habitats 
increases opportunities for local colonization and recolonization (Labonne et al. 2008, Grant et al. 2010, Grant 2011). Accordingly, occupancy dynamics are expected to be related to spatial layout of stream network habitat (Fagan 2002, Grant et al. 2009, Grant 2011), with particular locations in a network harboring more stable populations across seasons and years (Ovaskainen and Hanski 2003, Grant et al. 2007, Labonne et al. 2008). To maximize the ability to detect true population trends for species distributed in continuous habitat networks, it may be preferable to monitor locations where occupancy rates vary little among years or seasons. Detecting changes in such locations may reveal true declines in stream-level occupancy that could be overlooked under other sampling designs. Although microhabitat influences occupancy and local abundance, if locations of high occupancy occur predictably in relation to spatial or macrohabitat variables, monitoring strata can be chosen from a map of a stream network in the absence of more detailed microhabitat information.

Sampling designs for stream salamanders commonly include time-constrained searches (Barr and Babbitt 2002, Willson and Dorcas 2003, Marsh 2009), fixed effort searches (e.g., turning $n$ cobbles, $n$ consecutive trapping days; Marsh 2009, Lowe 2012), and fixed area searches (e.g., transects, quadrats; Barrett et al. 2010, Grant et al. 2010, Price et al. 2011). However, stream networks are continuous systems with spatial complexity that is often not captured in a given sampling design. Occupancy likely varies along habitat gradients and in response to characteristics arising from network structure (Benda et al. 2004, Grant et al. 2007) because many species occur more frequently in certain stream microhabitat types, which may also vary with life stage (Hairston 1987). Often, this issue is addressed with stratified random sampling, which may account for spatial variation but can lead to imprecise estimates of spatially referenced dynamics. The inclusion of covariates that describe spatial variation in occupancy or detection probabilities, such as proximity to confluences and seeps, may sufficiently describe spatial variation in these parameters without need for a generalized spatial model (Hines et al. 2010).

Monitoring programs have multiple uses (Lindenmayer and Likens 2010), only one of which is to identify trends in resource condition. For example, the National Park Service Inventory and Monitoring Program sets out to identify trends in amphibian occupancy as a Vital Sign; trends become targets of management action if there is evidence for declines in a component of the system (Fancy et al. 2009). Such results should be of particular interest to managers and agencies implementing similar programs because preliminary field data are often required to identify the most efficient design necessary to obtain useful and timely information on target populations (e.g., Bailey et al. 2007, Mattfeldt et al. 2009). If occupancy in a monitoring program is defined at the scale of the stream network (rather than at the level of individual segments), the variability of occupancy within a network suggests that the location of monitoring sites is of particular importance because dynamics (and thus inference to the population state) may differ depending on spatial selection of sites. Moreover, forecasts of climate change (i.e., earlier high flows, more frequent droughts, and longer lowflow periods in summer; Hayhoe et al. 2007, 2008), may decrease equilibrium occupancy probabilities or increase occupancy dynamics for stream salamander populations, and all locations within a network may not show identical responses. With the threat of climate change and expected regional changes in temperature and the timing and duration of precipitation (Hayhoe et al. 2007, 2008), stream amphibian populations and their habitats may need active management to maintain viable populations over the longterm to meet natural resource goals in parks, refuges, and other managed protected areas.

Our first objective was to determine where in a stream network occupancy was highest for 4 species of stream salamander, and evaluate relationships to measured habitat variables and stream-network position. We hypothesized that microhabitat covariates (e.g., cobble, silt) would influence detection of stream salamander species, and occupancy would be best estimated using covariates related to network position and stream size (Table 1). The second objective was to investigate, via simulation, the ability of different monitoring designs to detect different types of decline scenarios across multiple stream networks in a management unit; for example, there are often objectives to detect severe trends (e.g., 50\% decrease in occupancy) and increased dynamics (i.e., 50\% increase in extinction probability) over time periods as short as 5 years.

\section{STUDY AREA}

We conducted field sampling in 3 headwater streams in the Great Falls section of the Chesapeake and Ohio Canal National Historical Park $(\mathrm{CHOH})$ within Maryland, USA, which borders the northern side of the Potomac River. The dominant land cover adjacent to streams was upland forest, dominated by tulip poplar (Liriodendron tulipifera), oaks (Quercus spp.), hickories (Carya spp.), and red maple (Acer rubrum). The study area was bordered on one side by developed residential areas (50-145 units/km), had regular visitor use via trails that often bordered study streams, and was influenced by high white-tailed deer (Odocoileus virginianus) density and cover of exotic herbaceous species (Thomas et al. 2014). Temperatures in the study area were influenced by the maritime climate and urban heat island effects, and annual precipitation averaged $98 \mathrm{~cm}$ (Thomas et al. 2014).

\section{METHODS}

\section{Field Methods}

In 2010-2011, we sampled the entire length of 3 stream networks in $\mathrm{CHOH}$ from the lower junction of the stream with the canal to the upstream terminus of every tributary. We visited each stream in spring (Apr, May), summer (Jun, Jul), and fall (Aug, Sep) of each year. At the initial visit, we divided each stream network into $25-\mathrm{m}$ segments beginning from the downstream confluence, and marked each section to ensure continuity in capture locations across all visits. At each visit, a single observer worked upstream through a $25-\mathrm{m}$ 
Table 1. List of covariates used in models to examine expected positive $(+)$ and negative $(-)$ relationships ( $\mathrm{x}$ for unknown effect) among habitat variables and occupancy $(\Psi)$ or detection $(p)$ of 4 stream salamander species, northern two-lined salamander, dusky salamander, long-tailed salamander, and red salamander in 2010 at Chesapeake and Ohio Canal National Historical Park, Maryland, USA.

\begin{tabular}{|c|c|c|c|c|c|c|c|c|c|}
\hline \multirow[b]{2}{*}{ Variable } & \multicolumn{2}{|c|}{$\begin{array}{l}\text { Northern } \\
\text { two-lined } \\
\text { salamander }\end{array}$} & \multicolumn{2}{|c|}{$\begin{array}{c}\text { Dusky } \\
\text { salamander }\end{array}$} & \multicolumn{2}{|c|}{$\begin{array}{l}\text { Long-tailed } \\
\text { salamander }\end{array}$} & \multicolumn{2}{|c|}{$\begin{array}{c}\text { Red } \\
\text { salamander }\end{array}$} & \multirow[b]{2}{*}{ Definition } \\
\hline & $\Psi$ & $p$ & $\Psi$ & $p$ & $\Psi$ & $p$ & $\Psi$ & $p$ & \\
\hline m_riff & + & + & - & - & & & & & Total length of riffle/segment (m) \\
\hline m_run & & & & & + & - & + & - & Total length of run/segment $(\mathrm{m})$ \\
\hline m_pool & & & & & - & - & + & - & Total length of pool/segment (m) \\
\hline Depth & + & + & - & - & + & + & - & - & $\bar{x}$ segment depth \\
\hline Width & & & & & & & & & $\bar{x}$ segment width \\
\hline Sand & & & & & & & & & $\bar{x} \%$ sand \\
\hline Silt & & & & - & & - & & & $\bar{x} \%$ silt \\
\hline Detritus & & + & & + & & & & & $\bar{x} \%$ detritus \\
\hline $\mathrm{Cob}$ & & + & & + & & & & & $\bar{x} \%$ cobble \\
\hline Gravel & & & & & & & & & $\bar{x} \%$ gravel \\
\hline Muck & & & & + & & - & & + & $\bar{x} \%$ muck \\
\hline min_link & - & & - & & - & & - & & Min. distance to stream junction (up or downstream) \\
\hline useep & & & - & & & & - & & Min. upstream distance to seep \\
\hline minseep & & & - & & & & - & & Min. distance to seep (up or downstream) \\
\hline minslink & & & - & & & & - & & Min. distance to seep or link \\
\hline Stream & & & & & $\mathrm{x}$ & & $\mathrm{x}$ & & Accounts for unknown variation among streams \\
\hline Order & + & & - & & & & - & & Stream order of segment \\
\hline Visit & & $\mathrm{x}$ & & $\mathrm{x}$ & & $\mathrm{x}$ & & $\mathrm{x}$ & Accounts for unknown variation among visits \\
\hline
\end{tabular}

segment, turning all natural cover objects (rocks and woody debris $>6 \mathrm{~cm}$ ) in the stream channel and within $1 \mathrm{~m}$ of the stream margin on the bank, capturing all salamanders encountered. We used 3-pass temporary removal sampling at each survey occasion for every $25-\mathrm{m}$ segment to maximize detection (Mattfeldt and Grant 2007).

At each visit, we collected segment-level habitat data including water temperature, air temperature, $\mathrm{pH}$, and conductivity. We also collected fine-scale habitat data at each visit, including mean segment width, mean depth, mean substrate composition (6 categories: sand, silt, detritus, cobble, gravel, and muck, measured every $5 \mathrm{~m}$ ), and riffle, run, or pool locations to the nearest $0.5 \mathrm{~m}$ for each segment. All work was reviewed and approved by the United States Geological Survey (USGS) Patuxent Wildlife Research Center Animal Care and Use Committee (permit 2015-05).

\section{Analysis}

We used the full dataset (defining each 25 -m segment as a site) to investigate the influence of habitat and network covariates on each species. We used single-state, multi-season occupancy models to estimate initial segment-level occupancy $\left(\Psi_{2010}\right)$ and detection probabilities $(p)$ for 3 of the 4 stream salamander species encountered: northern two-lined salamander (Eurycea bislineata), long-tailed salamander (Eurycea longicauda), and red salamander (Pseudotriton ruber). Although this model assumes independence among sites and may bias the occupancy estimates toward zero (Hines et al. 2010), we expected to explain spatial autocorrelation sufficiently by specifying local and network-scale covariates in our occupancy models. Inclusion of these 2 levels of covariates relates directly to management when such covariates can be manipulated to affect salamander occupancy. For this analysis, we combined detections of each species from the 3 passes for each segment at each visit; we also assumed closure over the 3 visits each year.
We used a multi-season model to account for the nonindependence (i.e., a first-order Markovian process) of occupancy between years but with only 2 years of data were not able to estimate dynamic rates (i.e., local colonization $[\gamma]$ and local extinction $[\varepsilon])$ precisely; failing to account for non-independence between years (e.g., by analyzing data using a series of independent single-season models) is akin to an implicit dynamics model (MacKenzie 2006) and we wanted to avoid potential bias using such an approach.

For the fourth species, dusky salamander (Desmognathus fuscus), our sampling resulted in sufficient detections of multiple age-classes to allow the use of a multi-state, multiseason occupancy model (MacKenzie et al. 2009). This model is an extension of the single-state multi-season occupancy model to accommodate multiple occupancy states (e.g., age classes). The model allows estimation of initial species occupancy probability $\left(\Psi_{2010}\right)$ and the conditional probability $(R)$ that larvae (i.e., evidence of local reproduction) are present, given the segment is occupied by the species. Occurrence may then take one of several states: occupied by adults or juveniles, occupied by adults or juveniles and larvae, not occupied. We use a multi-season model to accommodate Markovian dependence of occupancy states between years. We estimated detection probabilities for adults and juveniles combined $\left(p_{1}\right)$, larvae $\left(p_{2}\right)$, and the probability of detecting larvae, given adults or juveniles were detected $(\delta)$. With additional years of data, the model would be able to estimate conditional occupancy probabilities (the probability the species occupies a segment $[C \Psi]$ and the probability larvae are present $[C R]$ ), which are conditional on the occupancy state in the previous year. In our study area, dusky salamanders metamorphose in late spring to early summer, so to avoid violating the closure assumption we included all individuals with $\leq 23 \mathrm{~mm}$ snout-vent length (SVL) in the larval age class for the sampling year, and 
counted those with $\geq 23 \mathrm{~mm}$ SVL in the adult-juvenile age class for that sampling year (Organ 1961, Danstedt 1975).

We expected detection would be related to segment-level habitat variables but occupancy would be better described by catchment-scale variables that described the position of the segment within the stream network (Table 1). We defined a set of a priori candidate models for each species based on our hypotheses, avoiding the inclusion of correlated variables (i.e., with $|r|>0.7$ ) in the same model. We estimated all occupancy model parameters using maximum likelihood in program PRESENCE (version 3.1, http://www.mbr-pwrc. usgs.gov/software/presence.html, accessed 11 Apr 2011). We used corrected Akaike's Information Criterion ( $\mathrm{AIC}_{c}$ ) to evaluate support for each model in the set, and we calculated model weights to allow evaluation of the evidence for a given hypothesis (conditional on the model set).

\section{Evaluating Design Tradeoffs}

We used the occupancy and detection estimates obtained from the data for the most common (dusky salamander) and least common (red salamander) species to investigate monitoring design tradeoffs over a 5-year timespan. Our objectives were to evaluate the effect of transect length and transect position on the ability of different monitoring designs to detect changes in occupancy and extinction probabilities.

For all simulations, we assumed a given monitoring program could sample 100 transects during each of 2 visits per sampling year. To simulate monitoring datasets, we first used the meter-scale detection data from our complete network surveys to divide the networks into contiguous $15-\mathrm{m}, 25-\mathrm{m}$, or $50-\mathrm{m}$ segments. We then used a simplified multi-season occupancy $\operatorname{model}(\Psi[$ order $], \gamma[],. \varepsilon[],. p[$ order $])$ for each dataset to obtain annual estimates of occupancy and detection for each species in first-, second-, and third-order areas of the stream networks (Strahler 1957). Because we also wanted to examine the effect of transect placement, we considered 3 different designs to allocate 100 transects among first-, second-, and third-order stream areas: equal allocation of transects among stream orders (33, 33, 34 sites; equal), headwater-preference allocation of transects (60, 20, 20 sites; headwater), and allocation roughly proportional to the occurrence on the landscape (40, 40, 20 sites; proportional). Thus, we examined the ability of 9 different program designs to detect each of 3 decline scenarios (Appendix A).

We used program GENPRES (Bailey et al. 2007) to simulate occupancy data for each transect length and placement combination for the 2 species using the order-specific occupancy and detection rates, and analyzed each simulated detection dataset in Program MARK (White and Burnham 1999) to estimate annual occupancy or rate parameters across all streams (Appendix A). We simulated 3 scenarios that represented information on amphibian populations across a unit that would be valuable to managers. The first scenario specified $\geq 50 \%$ decline in annual occupancy estimates over 5 years (dusky salamander $\Psi_{1}=0.9, \Psi_{5}=0.3$; red salamander $\Psi_{1}=0.23, \Psi_{5}=0.11$ ) resulting from an annual increase in local extinction rate of 0.1 per year (dusky salamander $\varepsilon_{1}=0.4$, $\varepsilon_{4}=0.7$; red salamander $\left.\varepsilon_{1}=0.6, \varepsilon_{4}=0.9\right)$. Five years is a relevant planning period for resource management in the National Park Service. The ability to detect declines in occupancy and the annual changes in extinction may allow managers to choose more specific actions accordingly.

The second scenario investigated a similar decline in occupancy over 5 years (dusky salamander $\Psi_{1}=0.8, \Psi_{5}=0.4$; red salamander $\left.\Psi_{1}=0.4, \Psi_{5}=0.09\right)$ as a result of a constant, higher extinction rate (dusky salamander $\varepsilon=0.4$; red salaman$\operatorname{der} \varepsilon=0.9$ ). We expected this scenario (stationary rates) to be easier to detect in the short (5 year) time frame. Because red salamanders were infrequently detected in our study, within scenario 2, we also included a separate simulation to test whether doubling the detection probability for this species would increase the ability of any design to detect changes in occupancy.

The third scenario examined our ability to estimate rate parameters by modeling data that simulated a system at equilibrium. Constant occupancy may be a result of colonization and extinction events near zero or rates that are compensatory (Martin et al. 2009). It is important to be able to differentiate among these situations in a management context, particularly because actions under consideration would directly affect rate parameters (e.g., translocation, assisted migration, removal). For scenario 3 , we used rate parameter and detection estimates from our field sampling (dusky salamander: $\gamma=0.3, \varepsilon=0.1$; red salamander: $\gamma=0.1$, $\varepsilon=0.1)$ as the generating model.

For each of the 3 scenarios, we considered the generating model (Appendix A) to be the alternative hypothesis; the null hypothesis was a model representing no change in local extinction, occupancy, or colonization and extinction equal to zero. We approximated power $(\alpha=0.05)$ from a noncentral chi-squared distribution using the chi-square statistic from the likelihood ratio test as the noncentrality parameter, $\lambda$ (Burnham et al. 1987, Bailey et al. 2007).

\section{RESULTS}

\section{Occupancy Modeling}

We detected all 4 species in both years of sampling and 3 of the 4 species on all sampling occasions (we did not detect longtailed salamanders in any segment during fall 2010). The bestsupported models for the northern two-lined salamander included variables on occupancy describing stream size (depth and order), and detection as a function of percent detritus with detection decreasing as detritus increased (Table 2). Occupancy (Fig. 1) and detection of northern two-lined salamanders were generally high, which was expected.

Results for the long-tailed salamander indicated differences in occupancy among the 3 stream networks sampled (Fig. 1) that were not accounted for by the habitat variables and large variation in detection among visits. We estimated the highest detection probability $(>0.5)$ for spring (Apr-May) surveys and the lowest $(<0.1)$ for fall (Aug-Sep). Top models (i.e., those with $\left.\mathrm{AIC}_{c}<2.0\right)$ for the long-tailed salamander included 2 variables describing stream habitat structure: length of runs $(\mathrm{m})$ on occupancy and length of pools $(\mathrm{m})$ on detection, with estimates indicating positive relationships in both cases (Table 2). 
Table 2. Best supported models (change in corrected Akaike's Information Criterion $\left[\Delta \mathrm{AIC}_{c}\right]<10$ ) of candidate sets investigating habitat and networkposition covariates on occupancy $(\Psi)$, colonization $(\gamma)$, extinction $(\varepsilon)$, and detection $(p)$ of 4 species of stream salamander, northern two-lined salamander, dusky salamander, long-tailed salamander, and red salamander in 2010 at Chesapeake and Ohio Canal National Historical Park, Maryland, USA. Statistics are AIC $c$ $\Delta \mathrm{AIC}_{c}$, AIC weight $\left(w_{i}\right)$, number of parameters in the model $(K)$, and -2 times the logarithm of the likelihood $(-2 \mathrm{LL})$.

\begin{tabular}{|c|c|c|c|c|c|c|}
\hline Model $^{\mathbf{a}}$ & $\mathrm{AIC}_{c}$ & $\Delta \mathrm{AIC}_{c}$ & $w_{i}$ & Model likelihood & $K$ & $-2 \mathbf{L L}$ \\
\hline \multicolumn{7}{|l|}{ Northern two-lined salamander } \\
\hline$\Psi$ (order), $\gamma(),. \varepsilon(),. p(\mathrm{det})$ & 659.91 & 0.00 & 0.5965 & 1.0000 & 6 & 647.91 \\
\hline$\Psi$ (order, depth), $\gamma(),. \varepsilon(),$.$p (det)$ & 661.73 & 1.82 & 0.2401 & 0.4025 & 7 & 647.73 \\
\hline$\Psi$ (order), $\gamma(),. \varepsilon(),$.$p (visit)$ & 662.50 & 2.59 & 0.1634 & 0.2739 & 10 & 642.50 \\
\hline \multicolumn{7}{|l|}{ Dusky salamander } \\
\hline$\Psi, R$ (minlink, depth), $\delta(),$.$p (visit, depth)$ & $1,240.05$ & 0.00 & 0.9997 & 1.0000 & 18 & $1,204.05$ \\
\hline \multicolumn{7}{|l|}{ Long-tailed salamander } \\
\hline$\Psi$ (stream, mrun), $\gamma(),. \varepsilon(),$.$p (visit, mpool)$ & 239.75 & 0.00 & 0.6410 & 1.0000 & 13 & 213.75 \\
\hline$\Psi$ (stream, mrun), $\gamma(),. \varepsilon(),$.$p (visit)$ & 240.91 & 1.16 & 0.3589 & 0.5599 & 12 & 216.91 \\
\hline \multicolumn{7}{|l|}{ Red salamander } \\
\hline$\Psi$ (useep), $\gamma(),. \varepsilon(),$.$p (mpool)$ & 374.32 & 0.00 & 0.5002 & 1.0000 & 6 & 362.32 \\
\hline$\Psi$ (useep, mpool), $\gamma(),. \varepsilon(),. p()$. & 376.92 & 2.60 & 0.1363 & 0.2725 & 6 & 364.92 \\
\hline$\Psi$ (useep), $\gamma(),. \varepsilon(),. p()$. & 378.68 & 4.36 & 0.0565 & 0.1130 & 5 & 368.68 \\
\hline$\Psi$ (useep, order), $\gamma(),. \varepsilon(),. p()$. & 378.74 & 4.42 & 0.0549 & 0.1097 & 6 & 366.74 \\
\hline$\Psi$ (mpool), $\gamma(),. \varepsilon(),. p()$. & 379.17 & 4.85 & 0.0443 & 0.0885 & 5 & 369.17 \\
\hline$\Psi$ (minslink), $\gamma(),. \varepsilon(),. p()$. & 379.92 & 5.60 & 0.0304 & 0.0608 & 5 & 369.92 \\
\hline$\Psi$ (order), $\gamma(),. \varepsilon(),. p()$. & 379.98 & 5.66 & 0.0295 & 0.0590 & 5 & 369.98 \\
\hline$\Psi$ (useep), $\gamma(),. \varepsilon(),$.$p (depth)$ & 380.02 & 5.70 & 0.0289 & 0.0578 & 6 & 368.02 \\
\hline$\Psi$ (useep), $\gamma(),. \varepsilon(),$.$p (muck)$ & 380.02 & 5.70 & 0.0289 & 0.0578 & 6 & 368.02 \\
\hline$\Psi$ (useep), $\gamma(),. \varepsilon(),$.$p (mrun)$ & 380.28 & 5.96 & 0.0254 & 0.0508 & 6 & 368.28 \\
\hline$\Psi$ (muck), $\gamma(),. \varepsilon(),. p()$. & 380.39 & 6.07 & 0.0240 & 0.0481 & 5 & 370.39 \\
\hline$\Psi$ (minseep), $\gamma(),. \varepsilon(),. p()$. & 381.73 & 7.41 & 0.0123 & 0.0246 & 5 & 371.73 \\
\hline$\Psi($ minlink $), \gamma(),. \varepsilon(),. p()$. & 382.00 & 7.68 & 0.0108 & 0.0215 & 5 & 372.00 \\
\hline$\Psi$ (depth), $\gamma(),. \varepsilon(),. p()$. & 382.26 & 7.94 & 0.0094 & 0.0189 & 5 & 372.26 \\
\hline
\end{tabular}

${ }^{a}$ Variables include order (stream order), det ( $\bar{x} \%$ detritus), depth ( $\bar{x}$ segment depth), visit (accounts for unknown variation among visits), minlink (min. distance to stream junction [up or downstream]), stream (accounts for unknown variation among streams), mrun (total length of run per segment), useep (min. upstream distance to seep), mpool (total length of pool per segment), minslink (min. distance to seep or link), muck ( $\bar{x} \%$ muck), minseep (min. distance to seep [up or downstream]), $R$ (the conditional probability that juveniles or larvae are present, given the segment is occupied by the species), and $\delta$ (probability of detecting larvae, given adults or juveniles were detected).

Occupancy of red salamanders was best described by proximity to an upstream seep, with estimates of $0.46 \pm 0.10$ (SE) in segments where seeps occurred and decreasing to near zero at distances $>250 \mathrm{~m}$ from a seep (Fig. 1). Detection was generally low $(<0.3)$, did not vary among seasons, and was negatively related to the amount of pool habitat in a segment (Table 2).

Species-level occupancy of dusky salamanders was best described by a network position covariate (min. distance to stream junction) and a habitat covariate (depth; Table 2), indicating the species had highest occupancy in shallow stream areas near confluences (Fig. 1). Top models (i.e., those with $\left.\mathrm{AIC}_{c}<2.0\right)$ for detection probability included depth and season (Table 2), with highest detection $(>0.8)$ in shallow stream areas in the early spring (Apr-May) and late summer (Aug-Sep). The probability of observing larvae given the species was detected was moderate (range $=0.3-0.7$ ), and generally highest in the headwaters.

\section{Monitoring Design Evaluation}

The headwater monitoring design had higher power to detect changes of occupancy and rate parameters in each of the 3 scenarios for dusky salamanders and red salamanders (Appendix A). Results for transect length were more variable, but across all species and scenarios, $25-\mathrm{m}$ transects were the most suitable as a balance between maximizing detection probability and precision in estimated rates of colonization and extinction.
At the level of effort we examined (100 transects, 2 visits/ year, 5 years), none of the designs had sufficient power to detect concurrent temporal changes in occupancy and a rate parameter (scenario 1; Appendix A). If changes in occupancy across a management unit are the main interest, $25-\mathrm{m}$ transects in all 3 designs and 50-m transects with a headwater design should be sufficient to estimate changes for dusky salamanders (scenario 2; Appendix A). Detection probability was too low to allow the same outcome for red salamanders in scenario 2, but doubling detection probability (e.g., with increased temporal replication or sampling methods targeted to the species; Mattfeldt and Grant 2007) would be sufficient to detect changes if implemented with any transect length in a headwater design (scenario 2; Appendix A). Results from scenario 3 indicate high power (near 100\%) in all transectdesign combinations to differentiate zero versus non-zero rate parameters for dusky salamanders (results not shown). Despite low detection probability for red salamanders, sufficient power to estimate rate parameters under constant occupancy is achieved if transects are placed primarily in headwater areas using $25-\mathrm{m}$ or $50-\mathrm{m}$ transects (scenario 3; Appendix A).

\section{DISCUSSION}

Long-term monitoring programs can fail to meet the information needs of land managers because of inadequate planning, or lack of timely evaluation (Cook et al. 2010). For 


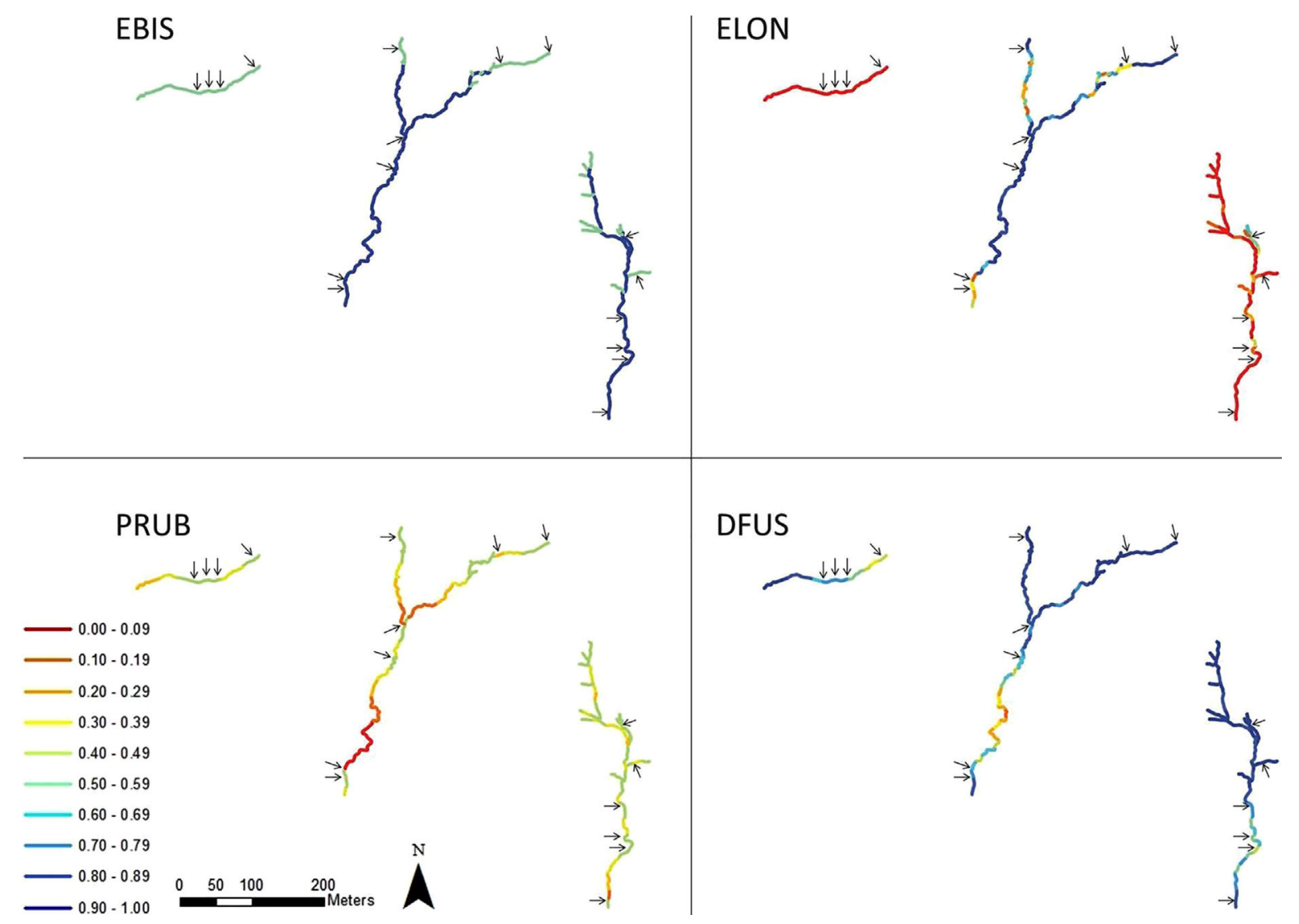

Figure 1. Occupancy probabilities in 2010 for each species in the 3 stream networks in our study at Chesapeake and Ohio Canal National Historical Park, Maryland, USA as estimated by the top model for each of 4 stream salamander species: northern two-lined salamander (EBIS), long-tailed salamander (ELON), red salamander (PRUB), and dusky salamander (DFUS). Arrows indicate locations of streamside seeps; seeps are also present at upstream terminus of all tributaries.

these reasons, we emphasize that monitoring programs should have clearly articulated objectives and hypotheses, methods that address imperfect detection and provide information on both the species of interest and habitat variables relevant to management decisions, and plans for periodic assessment to allow modification of objectives and methods to ensure the program continues to address research needs.

We expected that fine-scale microhabitat variables such as cobble and detritus would influence occupancy of each of the 4 species (Table 1); however, top models for all species were dominated by variables describing position within the stream network, stream size, or stream features (riffle, run, pool). These results are promising for planning studies and choosing locations for conservation in the eastern United States without intensive prior field work because catchment-scale information is often available from existing habitat maps (e.g., stream order, position of confluences) or easy to determine upon first visits to sites without a need to survey for salamander populations (e.g., seep, run, or pool locations). Indeed, habitat features may also be related to spatial position (Benda et al. 2004) and partially predictable from existing maps. However, for 1 species (long-tailed salamander), the variation in occupancy among different stream networks was not well captured by any of the covariates we measured. Other influences may be affecting occupancy patterns for this species, including land-use effects such as trail proximity, landscape influences such as flooding frequency, or connectivity to other populations. Previous researchers have associated long-tailed salamander populations with the presence of temporary pools (Anderson and Martino 1966, Petranka 2010), so stream surveys alone may not be sufficient to monitor occupancy changes for this species across a management unit.

Although useful for site selection for sampling or conservation, these large-scale habitat features may be far less conducive to active management. Variables that may be easier to manipulate (e.g., proportion of a streambed with gravel or cobble) appeared to have relatively little effect on occupancy of the species in our study, so any management action targeting these fine-scale habitat relationships may have limited effectiveness. Moreover, it is difficult to predict how climate change would affect large-scale factors such as network structure, and projections for increased droughts in the region (Hayhoe et al. 2007) could change the amount of headwater habitat available for occupancy. Because of the strong associations with headwater habitats for these and other salamander species (Hairston 1987), headwater segments should receive consideration for their particular contributions in conservation and management (Lowe and Likens 2005).

Large variation in detection probability among sites, visits, and species underscores the importance of estimating this 
value in any monitoring program to provide unbiased estimates of parameters of direct interest (e.g., site occupancy). Although some species had low detection probability (longtailed salamander, red salamander), our inference is that individuals were often present but were not likely to be seen on a given survey visit (i.e., false absence rates were fairly high for these species). Although covariates that best described detection varied among species, incorporation of this information in multi-species research programs would create sampling regimes such that timing of surveys and location of sites increase the cumulative detection probabilities of all species over the course of an entire season. Other studies have investigated sampling tradeoffs in regards to more sites or repeat visits; in most cases, the optimal design depends on the estimated detectability of the target species (Field et al. 2005, Mattfeldt et al. 2009, Guillera-Arroita and Lahoz-Monfort 2012). Moreover, optimal survey design is likely unique to each monitoring program based on parameters of interest, desired precision, and budget and logistical constraints (Wintle et al. 2010, Lindenmayer et al. 2013). However, our results can guide investigations of tradeoffs in sampling based on objectives, a critical step in ensuring the ability of a chosen design to generate unbiased estimates of desired state variables and rates for species of interest.

The monitoring program we evaluated was intended to detect trends in occupancy probability across multiple streams. Most managers are interested in detecting declines within a short time-frame to allow for more effective (and less costly) conservation actions to be implemented (Grant et al. 2013). None of the designs we investigated were sufficient to produce precise annual estimates of occupancy and a rate parameter, such as local extinction probability. This is not unexpected because stream salamander populations are generally presumed to be relatively stable (Green 2003), so colonization and extinction at the local population level is likely infrequent and difficult to estimate over a 5-year time frame. Moreover, because it is unlikely that declines would occur uniformly across a stream network, intensive effort over a longer time frame is required to ensure high power to detect declines in segment or network-level occupancy or annual variation in rate parameters. Monitoring programs that focus on estimating trends over a short time can be misleading when extrapolated to longer time series by overestimating the importance of rare events (Hecnar and M'Closkey 1997) or by simply lacking statistical power, leading to erroneous conclusions of population stability (Schmidt 2003). Further, the lifespan of the organism in question is important to consider as a frame of reference for trends because longer studies may be inadequate if they have not spanned at least 1 complete population turnover, which can vary across a species' range (Walls 2014). In our study system, for the species considered, empirical estimates of survival probabilities (Grant et al. 2010) indicate this may require a decade or more of monitoring.

In general, future multi-year studies should investigate the effects of macro- and micro-scale habitat variables and network structure on rate parameters because changes in colonization and extinction rates underlie changes in occupancy. More importantly, these covariates may have stronger or more interpretable effects on rate parameters than on occupancy patterns. Thus, collection of habitat and network data may aid decision making or management, but precise estimation of such effects may take more years and greater survey effort (Yackulic et al. 2014). If active management is a possibility, there is a cost to delaying action until after declines are detected (Grant et al. 2013), particularly in situations where the sampling effort may not be capable of precisely estimating declines. Monitoring programs that use management actions to investigate factors influencing occupancy are ideal for integrating active learning because hypotheses about the system can be tested (Williams 2009). Then, monitoring data can be used to inform tradeoffs and discriminate among management actions to best meet the objectives of stakeholders.

\section{MANAGEMENT IMPLICATIONS}

This study highlights the importance of considering spatial location for describing population dynamics of stream salamanders in the mid-Atlantic of the United States. When the state variable of interest is occupancy across an entire management unit, areas with consistently higher probability of occupancy are good targets for monitoring so as to minimize the risk of concluding erroneously that populations are declining. However, if populations in sections with high occupancy probability are also characterized by high abundance, marked declines in abundance may occur before changes in occupancy probability are detected. Robust estimation of colonization and extinction rates may be informative for developing management strategies to avoid population declines. The parameters of interest (e.g., occupancy, extinction rate) should be related to population trends within the context of management objectives. For example, a manager aiming to maintain occupancy in each stream network will require different information from one with the goal of sustaining mean occupancy across headwater areas within an entire park. Explicitly defining these aspects of a research or monitoring program will greatly increase chances of success.

\section{ACKNOWLEDGMENTS}

Any use of trade, product, or firm names is for descriptive purposes only and does not imply endorsement by the U.S. Government. This is contribution number 585 of the U.S. Geological Survey Amphibian Research and Monitoring Initiative. Fieldwork was completed with support from the Northeast Amphibian Research and Monitoring Initiative field crew and from the National Park Service National Capital Region Inventory and Monitoring Program.

\section{LITERATURE CITED}

Anderson,J.D., and P.J.Martino. 1966. The life history of Eurycea l. longicauda associated with ponds. American Midland Naturalist 75:257-279.

Bailey, L. L., J. E. Hines, J. D. Nichols, and D. I. MacKenzie. 2007. Sampling design trade-offs in occupancy studies with imperfect detection: examples and software. Ecological Applications 17:281-90.

Barr, G., and K. J. Babbitt. 2002. Effects of biotic and abiotic factors on the distribution and abundance of larval two-lined salamanders (Eurycea bislineata) across spatial scales. Oecologia 133:176-185. 
Barrett, K., B. S. Helms, C. Guyer, and J. E. Schoonover. 2010. Linking process to pattern: Causes of stream-breeding amphibian decline in urbanized watersheds. Biological Conservation 143:1998-2005.

Benda, L., N. L. Poff, D. Miller, T. Dunne, G. Reeves, G. Pess, M. Pollock, L. N. Poff, D. Miller, T. Dunne, G. Reeves, G. Pess, and M. Pollock. 2004. The network dynamics hypothesis: how channel networks structure riverine habitats. BioScience 54:413-427.

Burnham, K. P., D. R. Anderson, G. C. White, C. Brownie, and K. P. Pollock. 1987. Design and analysis methods for fish survival experiments based on release-recapture. American Fisheries Society Monographs 5.

Cook, C. N., M. Hockings, and R. Carter. 2010. Conservation in the dark? The information used to support management decisions. Frontiers in Ecology and the Environment 8:181-186.

Danstedt, R. T. J. 1975. Local geographic variation in demographic parameters and body size of Desmognatbus fuscus. Ecology 56:1054-1067.

Fagan, W. F. 2002. Connectivity, fragmentation, and extinction risk in dendritic metapopulations. Ecology 83:3243-3249.

Fancy, S. G., J. E. Gross, and S. L. Carter. 2009. Monitoring the condition of natural resources in US national parks. Environmental Monitoring and Assessment 151:161-174.

Field, S. A., A. J. Tyre, and H. P. Possingham. 2005. Optimizing allocation of monitoring effort under economic and observational constraints. Journal of Wildlife Management 69:473-482.

Grant, E. H. C. 2011. Structural complexity, movement bias, and metapopulation extinction risk in dendritic ecological networks. Journal of the North American Benthological Society 30:252-258.

Grant, E. H. C., L. E. Green, and W. H. Lowe. 2009. Salamander occupancy in headwater stream networks. Freshwater Biology 54:1370-1378.

Grant, E. H. C., W. H. Lowe, and W. F. Fagan. 2007. Living in the branches: population dynamics and ecological processes in dendritic networks. Ecology Letters 10:165-75.

Grant, E. H. C., J. D. Nichols, W. H. Lowe, and W. F. Fagan. 2010. Use of multiple dispersal pathways facilitates amphibian persistence in stream networks. Proceedings of the National Academy of Sciences of the United States of America 107:6936-40.

Grant, E. H. C., E. F. Zipkin, J. D. Nichols, and J. P. Campbell. 2013. A strategy for monitoring and managing declines in an amphibian community. Conservation Biology 27:1245-1253.

Green, D. M. 2003. The ecology of extinction: population fluctuation and decline in amphibians. Biological Conservation 111:331-343.

Guillera-Arroita, G., and J. J. Lahoz-Monfort. 2012. Designing studies to detect differences in species occupancy: power analysis under imperfect detection. Methods in Ecology and Evolution 3:860-869.

Hairston, N. G. 1987. Community ecology and salamander guilds. Cambridge University Press, New York, New York, USA.

Hayhoe, K., C. Wake, B. Anderson, X.-Z. Liang, E. Maurer, J. Zhu, J. Bradbury, A. DeGaetano, A. M. Stoner, and D. Wuebbles. 2008. Regional climate change projections for the Northeast USA. Mitigation and Adaptation Strategies for Global Change 13:425-436.

Hayhoe, K., C. P. Wake, T. G. Huntington, L. Luo, M. D. Schwartz, J. Sheffield, E. Wood, B. Anderson, J. Bradbury, A. DeGaetano, T. J. Troy, and D. Wolfe. 2007. Past and future changes in climate and hydrological indicators in the US Northeast. Climate Dynamics 28:381-407.

Hecnar, S. J., and R. T. M'Closkey. 1997. Spatial scale and determination of species status of the green frog. Conservation Biology 11:670-682.

Hines, J. E., J. D. Nichols, J. A. Royle, D. I. Mackenzie, A. M. Gopalaswamy, N. S. Kumar, and K. U. Karanth. 2010. Tigers on trails: occupancy modeling for cluster sampling. Ecological Applications 20:1456-66.

Labonne, J., V. Ravigné, B. Parisi, and C. Gaucherel. 2008. Linking dendritic network structures to population demogenetics: the downside of connectivity. Oikos 117:1479-1490.

Lindenmayer, D. B., and G. E. Likens. 2010. The science and application of ecological monitoring. Biological Conservation 143:1317-1328.
Lindenmayer, D. B., M. P. Piggott, and B. A. Wintle. 2013. Counting the books while the library burns: why conservation monitoring programs need a plan for action. Frontiers in Ecology and the Environment 11:549-555.

Lowe, W. H. 2012. Climate change is linked to long-term decline in a stream salamander. Biological Conservation 145:48-53.

Lowe, W. H., and G. E. Likens. 2005. Moving headwater streams to the head of the class. BioScience 55:196.

MacKenzie, D. I. 2006. Occupancy estimation and modeling: inferring patterns and dynamics of species occurrence. Academic Press, Burlington, Massachusetts, USA.

MacKenzie, D. I., J. D. Nichols, M. E. Seamans, and R. J. Gutiérrez. 2009. Modeling species occurrence dynamics with multiple states and imperfect detection. Ecology 90:823-835.

Marsh, D. 2009. Evaluating methods for sampling stream salamanders across multiple observers and habitat types. Applied Herpetology 6:211-226.

Martin, J., J. D. Nichols, C. L. McIntyre, G. Ferraz, and J. E. Hines. 2009. Perturbation analysis for patch occupancy dynamics. Ecology 90:10-16.

Mattfeldt, S. D., L. L. Bailey, and E. H. C. Grant. 2009. Monitoring multiple species: estimating state variables and exploring the efficacy of a monitoring program. Biological Conservation 142:720-737.

Mattfeldt, S. D., and E. H. C. Grant. 2007. Are two methods better than one? Area constrained transects and leaf litterbags for sampling stream salamanders. Herpetological Review 38:43-45.

Organ, J. A. 1961. Studies of the local distribution, life history, and population dynamics of the salamander genus Desmognathus in Virginia. Ecological Monographs 31:189-220.

Ovaskainen, O., and I. Hanski. 2003. How much does an individual habitat fragment contribute to metapopulation dynamics and persistence? Theoretical Population Biology 64:481-495.

Petranka, J. W. 2010. Salamanders of the United States and Canada. Smithsonian Institution Press, Washington, D.C., USA.

Price, S. J., K. K. Cecala, R. A. Browne, and M. E. Dorcas. 2011. Effects of urbanization on occupancy of stream salamanders. Conservation Biology 25:547-555.

Schmidt, B. R. 2003. Count data, detection probabilities, and the demography, dynamics, distribution, and decline of amphibians. Comptes Rendus Biologies 326:119-124.

Strahler, A. N. 1957. Quantitative analysis of watershed geomorphology. Transactions-American Geophysical Union 38:913.

Thomas, J. E., S. D. Costanzo, R. H. Kelsey, C. N. Bentsen, W. C. Dennison, P. Campbell, M. Lehman, M. Nortrup, C. Stubbs, M. Carter, B. Carlstrom, and J. Hitchcock. 2014. Chesapeake and Ohio Canal National Historical Park Natural Resource Condition Assessment. National Park Service, Fort Collins, Colorado, USA.

Walls, S. C. 2014. Identifying monitoring gaps for amphibian populations in a North American biodiversity hotspot, the southeastern USA. Biodiversity and Conservation 23:3341-3357.

White, G. C., and K. P. Burnham. 1999. Program MARK: survival estimation from populations of marked animals. Bird Study 46: S120-S139.

Williams, B. K. 2009. Markov decision processes in natural resources management: observability and uncertainty. Ecological Modelling 220:830-840.

Willson, J. D., and M. E. Dorcas. 2003. Effects of habitat disturbance on stream salamanders: implications for buffer zones and watershed management. Conservation Biology 17:763-771.

Wintle, B. A., M. C. Runge, and S. A. Bekessy. 2010. Allocating monitoring effort in the face of unknown unknowns. Ecology Letters 13:1325-1337.

Yackulic, C. B., J. D. Nichols, J. Reid, and R. Der. 2014. To predict the niche, model colonization and extinction. Ecology 96:16-23.

Associate Editor: Cynthia Paszkowski. 


\section{APPENDIX A: Simulation results}

Results of 3 modeling scenarios for 2 salamander species using rate parameters from occupancy models. Scenarios were combinations of 3 segment lengths $(15,25,50 \mathrm{~m})$ and 3 sampling designs (equal, headwater, proportional) for each scenario using simulated data under generating occupancy $(\Psi)$, colonization $(\gamma)$, extinction $(\varepsilon)$, and detection $(p)$. Power $(\alpha=0.05)$ is likelihood to reject $\mathrm{H}_{0}$, or power to detect the simulated change in occupancy or extinction, given by the model $\mathrm{H}_{\mathrm{a}}$. Combinations that yield power $>80 \%$ are indicated with an asterisk.

\begin{tabular}{|c|c|c|c|c|c|c|c|c|c|}
\hline Scenario & Species & $\begin{array}{l}\text { Segment } \\
\text { length }\end{array}$ & Design & $\begin{array}{c}\mathrm{H}_{0} \\
\text { deviance }\end{array}$ & $\begin{array}{c}\mathrm{H}_{\mathbf{a}} \\
\text { deviance }\end{array}$ & $\chi^{2}$ & df & $P$ & $\begin{array}{c}\text { Power } \\
(\%)\end{array}$ \\
\hline \multicolumn{10}{|c|}{$\begin{array}{l}\text { Scenario } 1 \text { : Decline in } \Psi \text {, increase in } \varepsilon \\
\mathrm{H}_{0}: \Psi(.), \gamma(.), \varepsilon(.), p(.) ; \\
\mathrm{H}_{\mathrm{a}}: \Psi(\mathrm{t}), \gamma(.), \varepsilon(\mathrm{t}), p(.)\end{array}$} \\
\hline & Dusky salamander & $15 \mathrm{~m}$ & Equal & 357.05 & 354.18 & 2.861 & 3 & 0.414 & 26 \\
\hline & & $15 \mathrm{~m}$ & Headwater & 630.08 & 625.03 & 5.049 & 3 & 0.168 & 44 \\
\hline & & $15 \mathrm{~m}$ & Proportional & 210.03 & 208.34 & 1.683 & 3 & 0.641 & 17 \\
\hline & & $25 \mathrm{~m}$ & Equal & 343.98 & 340.72 & 3.264 & 3 & 0.353 & 30 \\
\hline & & $25 \mathrm{~m}$ & Headwater & 404.68 & 400.84 & 3.840 & 3 & 0.279 & 35 \\
\hline & & $25 \mathrm{~m}$ & Proportional & 202.34 & 200.42 & 1.920 & 3 & 0.589 & 19 \\
\hline & & $50 \mathrm{~m}$ & Equal & 329.06 & 325.63 & 3.433 & 3 & 0.330 & 31 \\
\hline & & $50 \mathrm{~m}$ & Headwater & 387.13 & 383.09 & 4.039 & 3 & 0.257 & 36 \\
\hline & & $50 \mathrm{~m}$ & Proportional & 193.57 & 191.55 & 2.020 & 3 & 0.568 & 19 \\
\hline & Red salamander & $15 \mathrm{~m}$ & Equal & 148.08 & 147.74 & 0.339 & 3 & 0.953 & 7 \\
\hline & & $15 \mathrm{~m}$ & Headwater & 261.32 & 260.72 & 0.599 & 3 & 0.897 & 9 \\
\hline & & $15 \mathrm{~m}$ & Proportional & 87.10 & 86.90 & 0.200 & 3 & 0.978 & 6 \\
\hline & & $25 \mathrm{~m}$ & Equal & 152.51 & 152.05 & 0.454 & 3 & 0.929 & 8 \\
\hline & & $25 \mathrm{~m}$ & Headwater & 269.14 & 268.33 & 0.801 & 3 & 0.849 & 10 \\
\hline & & $25 \mathrm{~m}$ & Proportional & 89.71 & 89.44 & 0.267 & 3 & 0.966 & 7 \\
\hline & & $50 \mathrm{~m}$ & Equal & 175.18 & 174.65 & 0.529 & 3 & 0.913 & 8 \\
\hline & & $50 \mathrm{~m}$ & Headwater & 309.13 & 308.20 & 0.933 & 3 & 0.817 & 11 \\
\hline & & $50 \mathrm{~m}$ & Proportional & 103.04 & 102.73 & 0.311 & 3 & 0.958 & 7 \\
\hline \multicolumn{10}{|c|}{$\begin{array}{l}\text { Scenario 2: Decline in } \Psi \text {, constant } \varepsilon \\
\mathrm{H}_{0}: \Psi(.), \gamma(.), \varepsilon(.), p(.) \\
\mathrm{H}_{\mathrm{a}}: \Psi(\mathrm{t}), \gamma(.), \varepsilon(.), p(.)\end{array}$} \\
\hline & Dusky salamander & $15 \mathrm{~m}$ & Equal & 428.90 & 426.97 & 1.935 & 4 & 0.748 & 17 \\
\hline & & $15 \mathrm{~m}$ & Headwater & 756.88 & 753.47 & 3.415 & 4 & 0.491 & 28 \\
\hline & & $15 \mathrm{~m}$ & Proportional & 252.29 & 251.16 & 1.138 & 4 & 0.888 & 11 \\
\hline & & $25 \mathrm{~m}$ & Equal & 381.90 & 359.96 & 21.940 & 4 & $<0.001$ & $98^{*}$ \\
\hline & & $25 \mathrm{~m}$ & Headwater & 673.94 & 635.22 & 38.720 & 4 & $<0.001$ & $100^{*}$ \\
\hline & & $25 \mathrm{~m}$ & Proportional & 224.65 & 211.74 & 12.910 & 4 & 0.012 & $83^{*}$ \\
\hline & & $50 \mathrm{~m}$ & Equal & 417.09 & 410.03 & 7.062 & 4 & 0.133 & 54 \\
\hline & & $50 \mathrm{~m}$ & Headwater & 736.05 & 723.59 & 12.460 & 4 & 0.014 & $82^{*}$ \\
\hline & & $50 \mathrm{~m}$ & Proportional & 245.35 & 241.20 & 4.154 & 4 & 0.386 & 33 \\
\hline & Red salamander & $15 \mathrm{~m}$ & Equal & 128.15 & 126.06 & 2.087 & 4 & 0.720 & 18 \\
\hline & & $15 \mathrm{~m}$ & Headwater & 226.15 & 222.47 & 3.682 & 4 & 0.451 & 30 \\
\hline & & $15 \mathrm{~m}$ & Proportional & 75.38 & 74.15 & 1.227 & 4 & 0.874 & 12 \\
\hline & & $25 \mathrm{~m}$ & Equal & 134.22 & 132.01 & 2.209 & 4 & 0.697 & 19 \\
\hline & & $25 \mathrm{~m}$ & Headwater & 236.85 & 232.96 & 1.300 & 4 & 0.861 & 12 \\
\hline & & $25 \mathrm{~m}$ & Proportional & 78.95 & 77.65 & 3.899 & 4 & 0.420 & 31 \\
\hline & & $50 \mathrm{~m}$ & Equal & 151.69 & 147.60 & 4.093 & 4 & 0.394 & 33 \\
\hline & & $50 \mathrm{~m}$ & Headwater & 267.69 & 260.47 & 7.224 & 4 & 0.125 & 56 \\
\hline & & $50 \mathrm{~m}$ & Proportional & 89.23 & 86.82 & 2.408 & 4 & 0.661 & 20 \\
\hline & $\begin{array}{l}\text { Red salamander-double } \\
\text { detection probability }\end{array}$ & $15 \mathrm{~m}$ & Equal & 185.33 & 174.76 & 10.580 & 4 & 0.032 & 74 \\
\hline & & $15 \mathrm{~m}$ & Headwater & 327.06 & 308.39 & 18.660 & 4 & $<0.001$ & $95^{*}$ \\
\hline & & $15 \mathrm{~m}$ & Proportional & 109.02 & 102.80 & 6.221 & 4 & 0.183 & 49 \\
\hline & & $25 \mathrm{~m}$ & Equal & 175.46 & 167.62 & 7.848 & 4 & 0.097 & 60 \\
\hline & & $25 \mathrm{~m}$ & Headwater & 309.34 & 295.79 & 13.850 & 4 & 0.008 & $86^{*}$ \\
\hline & & $25 \mathrm{~m}$ & Proportional & 103.22 & 98.60 & 4.616 & 4 & 0.329 & 37 \\
\hline & & $50 \mathrm{~m}$ & Equal & 197.92 & 179.26 & 18.660 & 4 & $<0.001$ & $95^{*}$ \\
\hline & & $50 \mathrm{~m}$ & Headwater & 349.28 & 316.35 & 32.930 & 4 & $<0.001$ & $100^{*}$ \\
\hline & & $50 \mathrm{~m}$ & Proportional & 116.43 & 105.45 & 10.980 & 4 & 0.027 & 76 \\
\hline \multicolumn{10}{|c|}{$\begin{array}{l}\text { Scenario 3: Constant } \Psi \text {, non-zero } \varepsilon \text { and } \gamma \\
\mathrm{H}_{0}: \Psi(.), \gamma(0), \varepsilon(0), p(.) \\
\mathrm{H}_{\mathrm{a}}: \Psi(.), \gamma(.), \varepsilon(.), p(.)\end{array}$} \\
\hline & Red salamander & $15 \mathrm{~m}$ & Equal & 254.00 & 250.70 & 3.300 & 1 & 0.069 & 44 \\
\hline & & $15 \mathrm{~m}$ & Headwater & 448.23 & 442.41 & 5.824 & 1 & 0.016 & 67 \\
\hline & & $15 \mathrm{~m}$ & Proportional & 149.41 & 147.47 & 1.941 & 1 & 0.164 & 29 \\
\hline & & $25 \mathrm{~m}$ & Equal & 241.96 & 237.13 & 4.830 & 1 & 0.028 & 59 \\
\hline & & $25 \mathrm{~m}$ & Headwater & 426.99 & 418.47 & 8.523 & 1 & 0.004 & $83^{*}$ \\
\hline & & $25 \mathrm{~m}$ & Proportional & 142.33 & 139.49 & 2.841 & 1 & 0.092 & 39 \\
\hline & & $50 \mathrm{~m}$ & Equal & 298.40 & 292.61 & 5.791 & 1 & 0.016 & 67 \\
\hline & & $50 \mathrm{~m}$ & Headwater & 526.59 & 516.37 & 10.220 & 1 & 0.001 & $89^{*}$ \\
\hline & & $50 \mathrm{~m}$ & Proportional & 175.53 & 172.12 & 3.407 & 1 & 0.065 & 45 \\
\hline
\end{tabular}

